Article

\title{
Effective Biobased Phosphorus Flame Retardants from Starch-Derived bis-2,5-(Hydroxymethyl)Furan
}

\author{
Bob A. Howell * ${ }^{(1)}$ and Xiaorui Han \\ Department of Chemistry and Biochemistry, Center for Applications in Polymer Science, \\ Central Michigan University, Mt. Pleasant, MI 48858-0001, USA; han1x@cmich.edu \\ * Correspondence: bob.a.howell@cmich.edu
}

Received: 17 December 2019; Accepted: 24 January 2020; Published: 29 January 2020

check for updates

\begin{abstract}
A series of biobased phosphorus flame retardants has been prepared by converting starch-derived bis-2,5-(hydroxymethyl)furan to the corresponding diacrylate followed by Michael addition of phosphite to generate derivatives with phosphorus moieties attached via P-C bonds. All compounds behave as effective flame retardants in DGEBA epoxy resin. The most effective is the DOPO derivative, 2,5-di[(3-dopyl-propanoyl)methyl]furan. When incorporated into a DGEBA blend at a level to provide $2 \%$ phosphorus, a material displaying a LOI of 30, an UL 94 rating of $\mathrm{V} 0$ and a $40 \%$ reduction in combustion peak heat release rate compared to that for resin containing no additive is obtained. The analogous compounds generated from bisphenol A and tetrabromobisphenol A exhibit similar flame-retarding properties.
\end{abstract}

Keywords: biobased flame retardants; Phospha-Michael addition; furan additives; phosphorus derivatives of bisphenol and tetrabromobisphenol acrylates; green polymer additives; nontoxic flame retardants

\section{Introduction}

Polymeric materials have made a huge contribution to the development of modern society [1,2]. Apart from naturally-occurring polymers and modifications, these have generally been derived from petrochemicals. More recently, the generation of biobased polymers has gained interest [3]. For most applications polymeric materials must be flame retarded. Despite the popularity and effectiveness of traditional organohalogen flame retardants, in particular brominated aromatics, there has been a strong move away from the use of these materials. These compounds may be converted to volatile and toxic dioxins at high temperature [4]. However, the much larger concern arises from the migration of these compounds from a polymer matrix into which they have been incorporated. This is particularly a problem for waste items discarded in a landfill [5]. The flame retardants escape into the environment, are not biodegradable, bioaccumulate and pose risks to human health. Widespread human exposure to these materials has occurred and has been associated with a variety of disease states, most arising from endocrine disruption [6-9]. The negative impacts of human exposure to these compounds has promoted public pressure for the restriction of their use. This has occurred by both regulation and voluntary removal from the market [10-12]. The best candidates to replace organohalogen flame retardants are organophosphorus compounds [13,14]. In general, the toxicity of organophosphorus compounds is much lower than that observed for organohalogen counterparts [15-17]. Further, the effectiveness of organophosphorus flame retardants may be enhanced by the presence of compounds containing other elements, most notably sulfur [18-21], nitrogen [22-27], boron [28,29], or silicon [30-32]. Often the effectiveness of the presence of two flame-retarding compounds is touted as being synergistic. However, this is almost never the case. Usually, the impact of the two compounds on the suppression of flammability is not even additive. 
The development of polymer additives from naturally-occurring renewable materials is increasingly important [33]. The precursors to these materials are readily available, renewable annually, environmentally-benign, usually biodegradable, and generally nontoxic. They may be obtained from a variety of sources [34]. Further, the utilization of these materials is independent of the cost or availability of petrochemicals. Most prominently, the development of new flame retardants from biosources has been a focus [35-45]. Plant sources have long been the origin of many commercial materials [46]. More recently there has been an emphasis on starch from seed grains. A major source of starch, particularly in the United States, has been corn [47,48]. Starch may be hydrolyzed to afford glucose which can converted to many useful materials mainly through 5-hydroxymethylfurfural (HMF) [49-52]. Glucose may be reduced and then dehydrated to provide isosorbide, a diether diol, suitable for the generation of a range of phosphorus flame retardants [38-40]. Glucose, and other carbohydrates, may also serve as a source of bis-2,5-(hydroxymethyl)furan (BHMF). This difunctional alcohol has been used for the production of poly(ester)s [53-56] and plasticizers [57]. In this case, it was converted to the corresponding diacrylate. Michael addition of phosphite to the acrylate was then used to generate a series of bioderived phosphorus flame retardants containing P-C bonds [58-60].

\section{Results and Discussion}

The development of effective flame retardants from renewable biosources offers several advantages over traditional processes based on petrochemicals and is receiving increasing attention. The impetus for this development is a heightened concern for environmental quality and an increased awareness of the toxicity of traditional flame retardants. In this case, bioderived bis-2,5-(hydroxymethyl)furan has been utilized as the base for the generation of a series of phosphorus flame retardants. The diol was first converted to the diacrylate. Michael addition of phosphite to the diacrylate afforded the corresponding phosphorus derivatives [58]. This is illustrated in Scheme 1 for the preparation the DOPO derivative (DDMF).

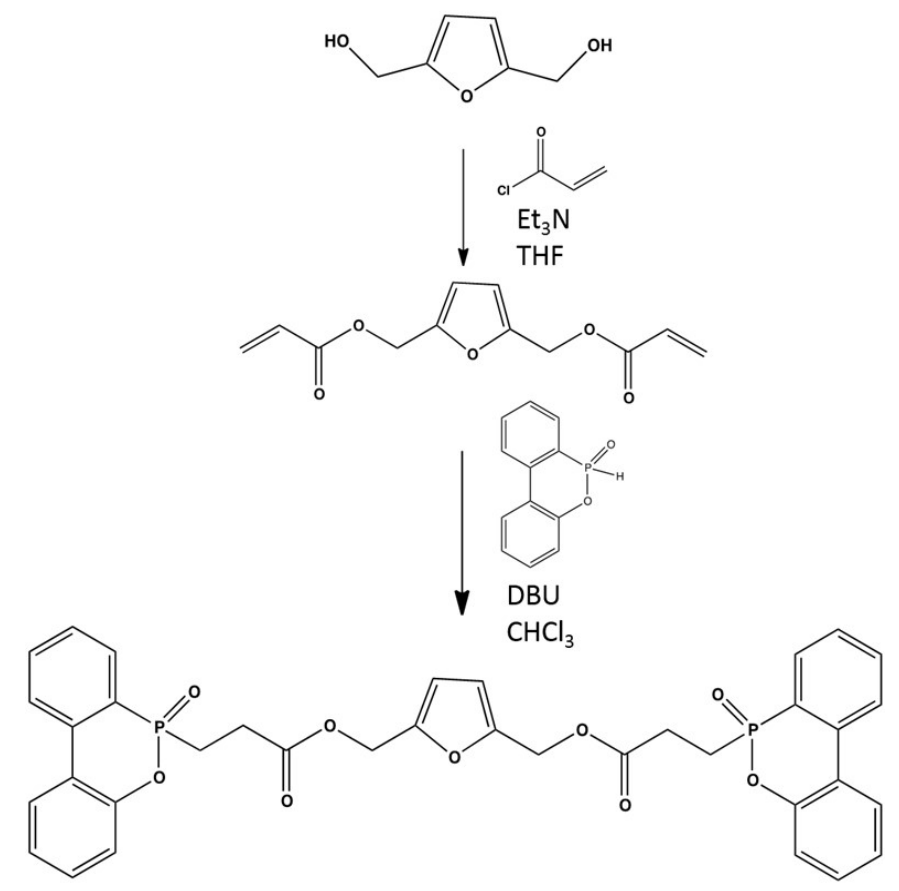

Scheme 1. Synthesis of 2,5-Di[(3-dopylpropanoyl)methyl]furan (DDMF).

The corresponding diethyl-(DEMF) and diphenylphosphite (DPMF) adducts were prepared in an analogous manner. The structures for all compounds were rigorously established using spectroscopic and thermal methods (see Experimental section); spectra may be found in Supplemental Material). 
Pertinent infrared absorptions for these compounds may be found in Table 1, proton NMR chemical shifts in Table 2 and the corresponding carbon- 13 chemical shifts in Table 3.

Table 1. Characteristic Infrared Absorptions $\left(\mathrm{cm}^{-1}\right)$ for Phosphorus Derivatives of 2,5bis(Hydroxymethyl)furan Diacrylate.

\begin{tabular}{|c|c|c|c|c|c|c|c|}
\hline & & 0 & & & & & \\
\hline \multirow[t]{4}{*}{$\begin{array}{l}\text { Phosphorus } \\
\text { Substituent }\end{array}$} & $\mathrm{C}_{\mathrm{sp} 3}-\mathrm{H}$ & $\mathrm{C}_{\mathrm{sp2} 2}-\mathrm{H}$ & $\mathrm{C}=\mathrm{O}$ & $\begin{array}{l}\text { Aromatic } \\
\text { Nucleus }\end{array}$ & $\mathrm{C}-\mathrm{O}-\mathrm{C}$ & $P=O$ & P-O-C \\
\hline & 3071 & 2923 & 1732 & 1598 & 1235 & 1197 & 910,757 \\
\hline & 3065 & 2930 & 1740 & 1598 & 1186 & 1162 & 927,762 \\
\hline & 3066 & $\begin{array}{l}2926, \\
2953\end{array}$ & 1737 & 1596 & 1232 & 1208 & 907,754 \\
\hline
\end{tabular}

Table 2. Characteristic ${ }^{1} \mathrm{H}-\mathrm{NMR}$ chemical shifts for phosphorus derivatives of 2,5bis(Hydroxymethyl)furan diacrylate. ${ }^{\text {a }}$<smiles>CP(C)(=O)CCC(=O)OCc1ccc(COC(=O)CCP(C)(C)=O)o1</smiles>

\begin{tabular}{|c|c|c|c|c|}
\hline $\begin{array}{l}\text { Phosphorus } \\
\text { Substituent }\end{array}$ & $\begin{array}{l}\text { Methylene Protons } \\
\text { Adjacent to Phosphorus }\end{array}$ & $\begin{array}{l}\text { Methylene Protons } \\
\text { Adjacent to Carbonyl }\end{array}$ & $\begin{array}{c}\text { Methylene } \\
\text { Protons Adjacent } \\
\text { to Furan Nucleus }\end{array}$ & Furan Protons \\
\hline & 2.36 & 2.68 & 4.98 & 6.31 \\
\hline & 2.46 & 2.85 & 5.02 & 6.37 \\
\hline & 2.02 & 2.58 & 4.99 & 6.32 \\
\hline
\end{tabular}

${ }^{a}$ In $\delta$ units with respect the resonance of tetramethylsilane as internal reference. 
Table 3. Characteristic ${ }^{13} \mathrm{C}-\mathrm{NMR}$ chemical shifts for phosphorus derivatives of 2,5bis(Hydroxymethyl)furan diacrylate. ${ }^{\text {a }}$

$\begin{gathered}\text { Carbon Atoms } \\ \text { Adjacent to } \\ \text { Phosphorus }\end{gathered}$
$\begin{gathered}\text { Carbon Atoms } \\ \text { Adjacent to } \\ \text { Carbonyl }\end{gathered}$

${ }^{\mathrm{a}}$ In $\delta$ units respect the resonance of tetramethylsilane as internal reference.

For comparison the corresponding DOPO derivatives of bisphenol A and tetrabromobisphenol A were prepared. Structures are shown in Figure 1.<smiles>CC(C)(c1ccc(OC(=O)CCP2(=O)Oc3ccccc3-c3ccccc32)cc1)c1ccc(OC(=O)CCP2(=O)Oc3ccccc3-c3ccccc32)cc1</smiles>

(a)

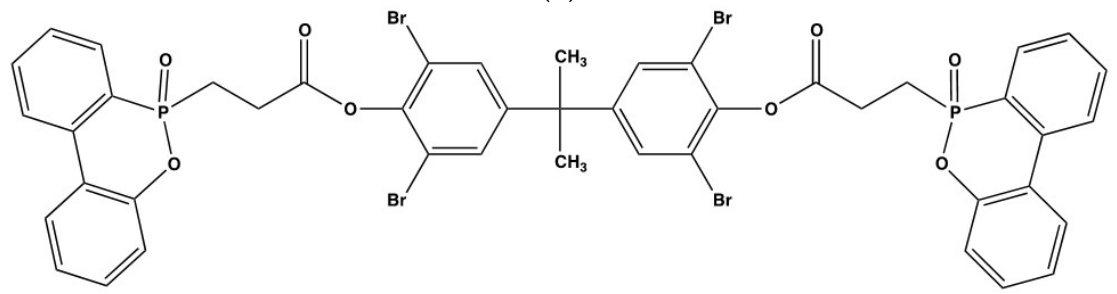

(b)

Figure 1. Structures for the DOPO adducts of bisphenol A and Tetrabromobisphenol A diacrylates. (a) 2,2-Di[4-(3-dopylpropanoyl)phenyl]propane (DDPP); (b) 2,2-Di[3,5-dibromo-4-(3dopylpropanoyl)phenyl]propane (DBDPP).

For assessment of the effectiveness of these compounds, blends with DGEBA epoxy at levels to provide $1 \%$ or $2 \%$ phosphorus and in two cases $5 \%$ phosphorus were prepared [58]. The flammability of the blends was determined using limiting oxygen index (LOI), microscale combustion calorimetry (MCC), and the underwriter Laboratories vertical burn test (UL94). Results are presented in Table 4. 
Table 4. Flammability data for blends of flame retardants with DGEBA epoxy resin.

\begin{tabular}{|c|c|c|c|c|c|}
\hline Flame Retardants Structure & $\begin{array}{l}\text { Loading of Additive } \\
(w g t \%)^{a}\end{array}$ & $\begin{array}{c}\text { Loading of } \\
\text { Phosphorus (wgt } \% \text { ) }\end{array}$ & $\mathrm{LOI}^{\mathrm{c}}$ & UL-94 Designation & $\operatorname{PHRR}(W / g)^{d}$ \\
\hline & 8 & 1 & 24.2 & - & 391 \\
\hline & 17 & 2 & 24.6 & - & 363 \\
\hline & 41 & 5 & 27.0 & V1 & 350 \\
\hline & 11 & 1 & 24.5 & - & 420 \\
\hline & 23 & 2 & 25.1 & - & 333 \\
\hline & 57 & 5 & 26.9 & V0 & 246 \\
\hline & 11 & 1 & 28.4 & V1 & 344 \\
\hline & 22 & 2 & 29.1 & V0 & 305 \\
\hline & 12 & 1 & 28.6 & V0 & 449 \\
\hline & 25 & 2 & 30.3 & V0 & 330 \\
\hline & 17 & 1 & 28.1 & V0 & 320 \\
\hline & 35 & 2 & 30.4 & V0 & 262 \\
\hline
\end{tabular}

${ }^{a}$ Weight percent of additive in DGEBA blend. ${ }^{\mathrm{b}}$ Weight percent of phosphorus in DGEBA blend. ${ }^{\mathrm{c}}$ Limiting Oxygen Index (LOI). ${ }^{\mathrm{d}}$ Microscale Combustion Calorimetry. 
As may be noted the presence of any of the additives sharply decreases the flammability compared to that for epoxy containing no flame retardant (LOI 19, PHRR $498 \mathrm{~W} / \mathrm{g}$, unrated in UL 94). For the derivatives of bis-2,5-(hydroxymethyl)furan, the DOPO adduct is the most effective. At a loading to provide $2 \%$ phosphorus in the blend, an LOI of 29.1, a PHRR of $305 \mathrm{~W} / \mathrm{g}$ and a UL 94 rating of V0 are observed. Derivatives of DOPO (low level of oxygenation at phosphorus) are predominately gas-phase active and function by extruding PO radical to the gas phase to quench combustion propagating reactions [61-66]. On the other hand, derivatives of diethyl- and diphenylphosphite are probably not gas-phase active and a higher loading ( $5 \%$ phosphorus) of these additives is required to achieve comparable flame retardancy.

A comparison of the effectiveness of the DOPO derivatives of the diacrylates of bis-2,5-(hydroxymethyl)furan, bisphenol A and tetrabromobisphenol A is presented in Table 5.

Table 5. Flammability of blends (2\% Phosphorus) of the 9,10-Dihydro-9-oxaphosphaphenanthrene10-oxide (DOPO) adducts of 2,5-bis(Hydroxymethyl)furan diacrylate, bisphenol A Diacrylate, and tetrabromobisphenol A diacrylate with DGEBA epoxy.

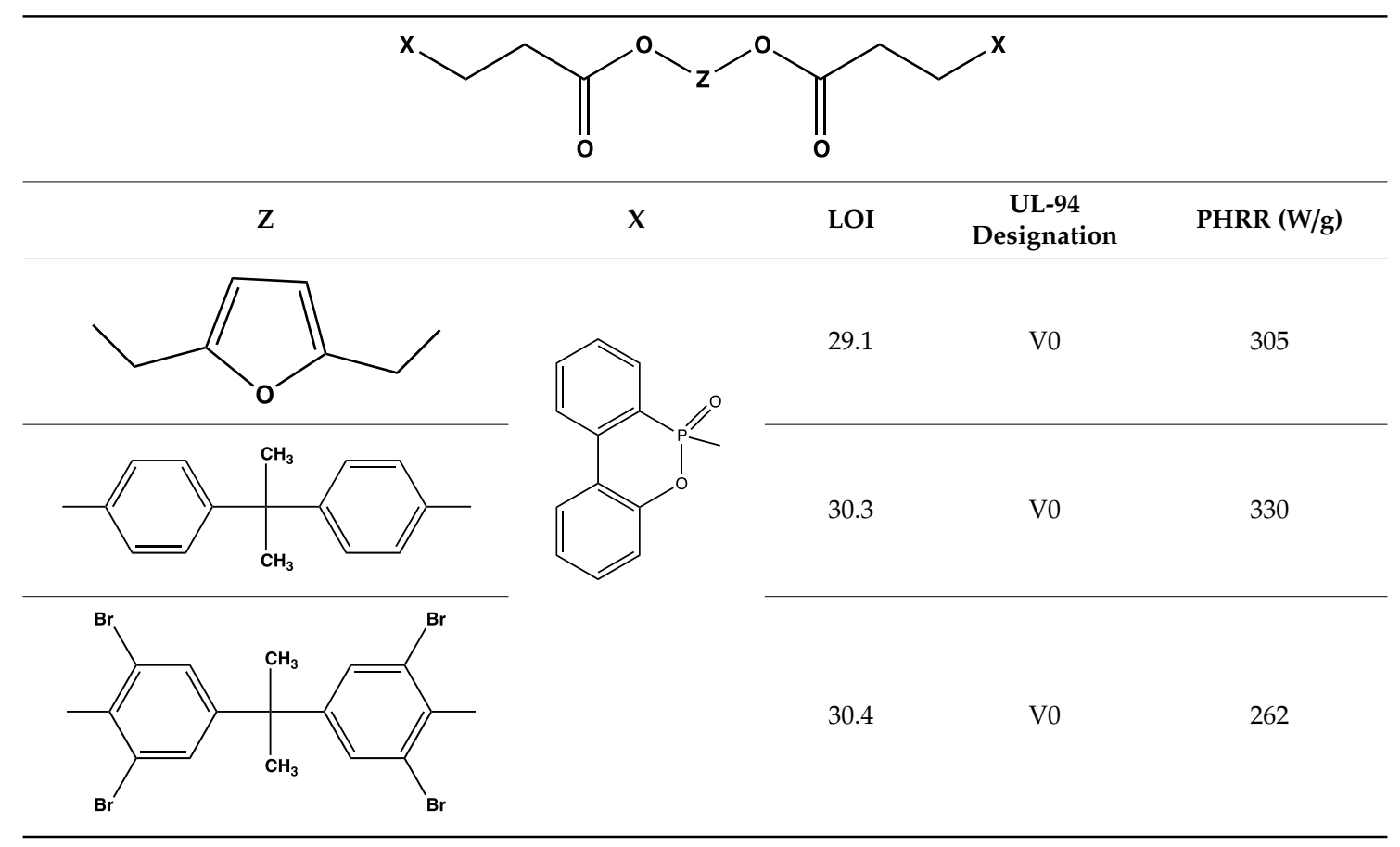

At a loading to provide $2 \mathrm{wgt} \%$ phosphorus, the impact of the additives is quite similar: LOI of 30, 40\% reduction in PHRR and a V0 UL 94 rating. Certainly, the impact of the furan derivative is comparable to that of the corresponding bisphenyl compounds. It is interesting that the brominated bisphenyl compound is little more effective than the analogous compound containing no bromine $[67,68]$. This may suggest that phosphorus is primarily responsible for the flame retardant effect.

\section{Materials and Methods}

\subsection{Materials}

Common solvents and reagents were from commercial sources and were purified as appropriate prior to use [58]. bis-2,5-(Hydroxymethyl)furan (BHMF) was supplied by PennAkem, LLC (Nashville, TN, USA). Diphenylchlorophossphate was provided by ICL-IPAmerica, Inc. (Ardsely, NY, USA) 9,10-Dihydro-9-oxaphosphaphenanthrene-10-oxide (DOPO) was from TCI (Portland, OR USA). The diglycidyl ether of bisphenol A (DGEBA) was supplied by the Dow Chemical Company (Midland, MI, USA). 


\subsection{Methods and Instrumentation}

Instrumentation and methods for characterization using spectroscopic, chromatographic and thermal techniques have been described previously [58]. Infrared spectra were obtained by attenuated total reflectance (ATR) using a Thermo Scientific (Waltham, MA, USA) Nicolet 380 FT-IR spectrophotomerter. Absorptions were recorded in wavenumbers $\left(\mathrm{cm}^{-1}\right)$, and absorption intensities were classified in the usual fashion as very weak (vw), weak (w), medium (m), strong (s), and very strong (vs) relative to the strongest band in the spectrum. Nuclear magnetic resonance (NMR) spectra were obtained using a 5-15\% solution in deuterochloroform or dimethylsulfoxide- $d_{6}$ and a Varian (Santa Clara, CA, USA) Mercury $300 \mathrm{MHz}$ or an INOVA $500 \mathrm{MHz}$ spectrometer. Proton and carbon chemical shifts are reported in parts per million $(\delta)$ with respect to tetramethylsilane (TMS) as an internal reference $(\delta=0.00)$. Phosphorus chemical shifts are in $\delta$ with respect of triphenylphosphate as internal reference $(\delta=-18.00)$. Electrospray ionization mass spectrometry (ESI-MS) was carried out using a Waters (Milford, MA, USA) Acquity/LCT Premier XE unit with samples introduced as dilute solutions in acetonitrile/water. Matrix assisted laser desorption ionization (MALDI) time of flight mass spectrometry was performed using a Bruker (Billerica, MA, USA) Daltonics Autoflex unit and 2,6-dihydroxybenzoic acid as matrix. Thermal transitions were determined by differential scanning calorimetry (DSC) using a TA instruments (New Castle, DE, USA) Q2000 instrument. Samples, contained in standard aluminum pans, were analyzed at a heating rate of 5 or $10{ }^{\circ} \mathrm{C} \mathrm{min}^{-1}$. The cell was subject to a constant purge of dry nitrogen at $50 \mathrm{~cm}^{3} \mathrm{~min}^{-1}$. Thermogravimetry was performed using a TA instruments Q500 instrument. Typically, a heating rate of 5 or $10{ }^{\circ} \mathrm{C} \mathrm{min}^{-1}$ was used. Samples (4-10 mg) were contained in a platinum pan. The sample compartment was purged with dry nitrogen at $50 \mathrm{~cm}^{3} \mathrm{~min}^{-1}$ during analysis. Peak heat release rates were determined using a Fire Testing Technology, Ltd. (East Grinstead, UK) (FTT) microscale combustion calorimeter, model FAA-PCFC. Limiting oxygen index values were determined using an FTT Oxygen Index unit. Vertical burn tests were conducted in an FTT UL 94 test chamber.

\subsection{Test Specimen}

Standard plaques for flammability testing were prepared from DGEBA epoxy using 2-ethyl-4-methylimidazole as hardener [58]. Samples were prepared by dissolving sufficient additive to provide a loading of one percent phosphorus in digycidyl ether of bisphenol A (DGEBA) epoxy at $90^{\circ} \mathrm{C}$. Hardener 2-ethyl-4-methylimidazole was added, mixed thoroughly, and the whole was poured into Teflon molds of appropriate dimensions which had been allowed to equilibrate at $95{ }^{\circ} \mathrm{C}$. The blends were cured initially at $95{ }^{\circ} \mathrm{C}$ for $1.5 \mathrm{~h}$ and then at $130^{\circ} \mathrm{C}$ for $1.5 \mathrm{~h}$. The samples were then allowed to cool slowly $\left(0.6^{\circ} \mathrm{C} / \mathrm{min}\right)$ to room temperature.

\subsection{Flammability Testing}

Flammability testing was accomplished using standard methods: limiting oxygen index (LOI; ASTM D2863-13), microscale combustion and calorimetry (MCC; ASTM D7309-07a), and the UL 94 vertical burn test (ASTM D3801-06).

\subsection{Synthesis}

The bis-acrylates of bis-2,5-(hydroxymethyl)furan (BHMF), bisphenol A (BPA), and tetrabromobisphenol A (TBBPA) were prepared by treating the appropriate diol with acryloyl chloride in the presence of triethylamine [58].

bis-2,5-(Hydroxymethyl)furan Diacrylate. To a stirred solution of $21.60 \mathrm{~g}(0.17 \mathrm{~mol})$ of bis-2,5-(hydroxymethyl)furan and $50 \mathrm{~mL}(0.37 \mathrm{~mol})$ of triethylamine, $200 \mathrm{~mL}$ of anhydrous THF maintained near $0{ }^{\circ} \mathrm{C}$ (external ice bath) was added, dropwise, over a period of $2 \mathrm{~h}$, a solution of $30 \mathrm{~mL}$ $(0.37 \mathrm{~mol})$ of acryloyl chloride in $150 \mathrm{~mL}$ of anhydrous THF. The resulting mixture was allowed to warm to room temperature and stirred for $6 \mathrm{~h}$. Water $(200 \mathrm{~mL})$ was added dropwise, followed by $200 \mathrm{~mL}$ 
diethyl ether. The layers were separated and the ether solution was washed, successively, with three $80-\mathrm{mL}$ portions of $5 \%$ aqueous hydrochloric acid solution, $80 \mathrm{~mL}$ of $5 \%$ aqueous sodium hydroxide solution and $80 \mathrm{~mL}$ of saturated aqueous sodium chloride solution. The ether solution was dried over anhydrous sodium sulfate and the solvent was removed by rotary evaporation at reduced pressure. The crude product was purified by column chromatography (silica gel; 3:1 ethyl-acetate/hexane as eluent) to provide $29.08 \mathrm{~g}$ (72.4\% yield) of the diacrylate as a colorless oil: $\mathrm{T}_{\mathrm{dec}} 128^{\circ} \mathrm{C}$ (TGA); FTIR ( $\mathrm{cm}^{-1}$, ATR) $3045(\mathrm{w}) \mathrm{C}_{\mathrm{sp} 2}-\mathrm{H}, 2956(\mathrm{w}), 2834(\mathrm{w}) \mathrm{C}_{\mathrm{sp} 3}-\mathrm{H}, 1721$ (vs) ester carbonyl, $1634(\mathrm{w}) \mathrm{C}=\mathrm{C}, 1613$ $(\mathrm{m})$ aromatic nucleus, $1182(\mathrm{vs}) \mathrm{C}-\mathrm{O} ;{ }^{1} \mathrm{H}-\mathrm{NMR}\left(\delta\right.$, DMSO- $\left.d_{6}\right) 5.02$ (s, methylene protons), 5.78-6.39 (m, $6 \mathrm{H}, \mathrm{ABX}$ pattern over a singlet, furan and phenyl protons); ${ }^{13} \mathrm{C}-\mathrm{NMR}\left(\delta\right.$, DMSO- $\left.d_{6}\right) 58.3$ (methylene carbon atoms), 112.5, 150.5 (furan carbon atoms), 128.3, 132.8 (vinylic carbon atoms), 165.6 (carbonyl carbon atoms); MS (ESI, $m / z) 259.03[\mathrm{M}+\mathrm{Na}]^{+}, 275.02[\mathrm{M}+\mathrm{K}]^{+}$.

Other acrylates were prepared in an analogous manner.

Bisphenol A Diacrylate. M.p. $89^{\circ} \mathrm{C}$ (DSC); $\mathrm{T}_{\mathrm{dec}} 431^{\circ} \mathrm{C}$ (TGA); FTIR ( $\mathrm{cm}^{-1}$, ATR) 3086 (w) C $\mathrm{csp}_{2}-\mathrm{H}, 2971$ (m) $2873(\mathrm{w}) \mathrm{C}_{\mathrm{sp} 3}-\mathrm{H}, 1750$ (s) ester carbonyl, 1633(w) C=C, 1508 (s) aromatic nucleus; ${ }^{1} \mathrm{H}-\mathrm{NMR}(\delta$, $\left.\mathrm{CDCl}_{3}\right) 1.69$ (s, $6 \mathrm{H}$, methyl protons), 5.96-6.66 ( $\mathrm{ABX}$ pattern, $6 \mathrm{H}$, vinylic protons), 7.16 ( $\mathrm{AB}$ pattern, $8 \mathrm{H}$, aromatic protons); ${ }^{13} \mathrm{C}-\mathrm{NMR}\left(\delta, \mathrm{CDCl}_{3}\right) 31.0$ (methyl carbon atoms), 42.5 (quaternary carbon atoms), 128.0, 132.5 (vinylic carbon atoms), 120.9, 127.9, 147.9, 148.5 (aromatic carbon atoms), 164.6 (carbonyl carbon atoms).

Tetrabromobisphenol A Diacrylate. $\mathrm{T}_{\mathrm{dec}} 345^{\circ} \mathrm{C}$ (TGA); FTIR ( $\mathrm{cm}^{-1}$, ATR) $3098(\mathrm{w}) \mathrm{C}_{\mathrm{sp} 2}-\mathrm{H}, 2971(\mathrm{w})$, $2873(\mathrm{w}) \mathrm{C}_{\mathrm{sp} 3}-\mathrm{H}, 1750(\mathrm{~s})$ ester carbonyl, $1633(\mathrm{w}) \mathrm{C}=\mathrm{C}, 1605(\mathrm{~m})$ aromatic nucleus, $1182(\mathrm{~s}) \mathrm{C}-\mathrm{O}$; ${ }^{1} \mathrm{H}-\mathrm{NMR}\left(\delta, \mathrm{CDCl}_{3}\right) 1.62$ (s, methyl protons), 6.09-6.78 (ABX pattern, $6 \mathrm{H}$, vinylic protons), $7.40(\mathrm{~s}, 4 \mathrm{H}$, aromatic protons); ${ }^{13} \mathrm{C}-\mathrm{NMR}\left(\delta, \mathrm{CDCl}_{3}\right) 29.8$ (methyl carbon atoms), 43.1 (quaternary carbon atoms), 126.2, 136.1 (vinylic carbon atoms), 117.8, 130.7, 144.3, 150.4 (aromatic carbon atoms), 162.3 (carbonyl carbon atoms).

The acrylate esters of bis-2,5-(hydroxymethyl)furan, bisphenol A and tetrabromobisphenol A were converted to phosphorus derivatives by Michael addition of phosphites using a previously described procedure [58].

2,5-Di[(3-dopylpropanoyl)methyl]furan (DDMF). A solution of $20.61 \mathrm{~g}(0.095 \mathrm{~mol})$ of DOPO, $5.7 \mathrm{~mL}$ $(0.038 \mathrm{~mol})$ of 1,8-diazabicycloundec-7-ene and $9.01 \mathrm{~g}(0.038 \mathrm{~mol})$ of bis-2,5-(hydroxymethyl)furan diacrylate in $75 \mathrm{~mL}$ of chloroform was stirred at $65^{\circ} \mathrm{C}$ for $4 \mathrm{~h}$. The solution was allowed to cool to room temperature and washed, successively with three $20-\mathrm{mL}$ portions of $5 \%$ aqueous hydrochloric acid solution, $20 \mathrm{~mL}$ of $5 \%$ aqueous sodium hydroxide solution and $20 \mathrm{~mL}$ of saturated aqueous sodium chloride solution. The chloroform solution was dried over anhydrous sodium sulfate and the solvent was removed by rotary evaporation at reduced pressure. The crude product was purified by column chromatography (silica gel; 5:3 ethyl acetate/hexane as eluent) to afford $23.45 \mathrm{~g}(92.10 \%$ yield) of DDMF as a white solid: m.p. $47^{\circ} \mathrm{C}$ (DSC), $\mathrm{T}_{\mathrm{dec}} 352^{\circ} \mathrm{C}$ (TGA); FTIR (cm ${ }^{-1}$, ATR) $3071(\mathrm{w}) \mathrm{C}_{\mathrm{sp} 2}-\mathrm{H}, 2923$ (w) $\mathrm{C}_{\mathrm{sp} 3}-\mathrm{H}, 1732$ (vs) ester carbonyl, 1598 (w) aromatic nucleus, 1235 (vs) C-O, 1197 (vs) P=O, 910 (s), 757 (s) P-O-C; ${ }^{1} \mathrm{H}-\mathrm{NMR}\left(\delta, \mathrm{CDCl}_{3}\right) 2.36(\mathrm{~m}, 4 \mathrm{H}$, methylene protons adjacent to phosphorus), $2.68(\mathrm{~m}, 4 \mathrm{H}$, methylene protons adjacent to carbonyl groups), 4.98 (s, $4 \mathrm{H}$, methylene protons adjacent to oxygen and a furan nucleus), 6.31 (s, $2 \mathrm{H}$, furan aromatic protons), 7.18-7.98 (m, 16H, dopyl protons); ${ }^{13} \mathrm{C}-\mathrm{NMR}$ $\left(\delta, \mathrm{CDCl}_{3}\right)$ 23.2, 26.3, 58.1 (methyl carbon atoms), 111.9, 120.4, 123.0, 123.9, 124.8, 125.2, 128.6, 130.1, $130.7,133.5,135.8,148.5,149.2,164.0$ (furan and dopyl carbon atoms), 171.8 (carbonyl carbon atoms); MS (ESI, $m / z), 669.13[\mathrm{M}+\mathrm{H}]^{+}, 691.11[\mathrm{M}+\mathrm{Na}]^{+}, 707.08[\mathrm{M}+\mathrm{K}]^{+}$.

Other adducts were prepared in an analogous manner.

2,5-Di[(3-diethylphosphonatopropanoyl)methyl]furan (DEMF). $\mathrm{T}_{\mathrm{dec}} 181^{\circ} \mathrm{C}$ (TGA); FTIR ( $\mathrm{cm}^{-1}$, ATR) 3066 $(\mathrm{w}) \mathrm{C}_{\mathrm{sp} 2}-\mathrm{H}, 2953(\mathrm{w})$ and $2926(\mathrm{w}) \mathrm{C}_{\mathrm{sp} 3}-\mathrm{H}, 1737$ (vs) ester carbonyl, $1596(\mathrm{w})$ aromatic nucleus, 1232 (vs) $\mathrm{C}-\mathrm{O}, 1208$ (vs) $\mathrm{P}=\mathrm{O}, 907$ (s), 754 (s) $\mathrm{P}-\mathrm{O}-\mathrm{C} ;{ }^{1} \mathrm{H}-\mathrm{NMR}\left(\delta, \mathrm{CDCl}_{3}\right) 1.26$ (m, 12H, methyl protons), 
$2.02(\mathrm{~m}, 4 \mathrm{H}$, methylene protons adjacent to phosphorus), $2.58(\mathrm{~m}, 4 \mathrm{H}$, methylene protons adjacent to carbonyl groups), $4.03(\mathrm{~m}, 8 \mathrm{H}$, methylene protons on ethyl groups), $4.99(\mathrm{~s}, 4 \mathrm{H}$, methylene protons adjacent to oxygen and a furan nucleus), 6.32 (s, $2 \mathrm{H}$, furan protons); ${ }^{13} \mathrm{C}-\mathrm{NMR}\left(\delta, \mathrm{CDCl}_{3}\right) 16.4$ (methyl carbon atoms), 20.9 (methylene carbon atoms adjacent to phosphorus), 27.4, 58.3, 62.0 (methylene carbon atoms), 111.7, 149.9 (furan carbon atoms), 171.6 (carbonyl carbon atoms); MS (ESI, $\mathrm{m} / \mathrm{z}$ ), 513.13 $[\mathrm{M}+\mathrm{H}]^{+}, 535.07[\mathrm{M}+\mathrm{Na}]^{+}, 551.09[\mathrm{M}+\mathrm{K}]^{+}$.

2,5-Di[(3-diphenylphosphonatopropanoyl)methyl]furan (DPMF). $\mathrm{T}_{\mathrm{dec}} 198^{\circ} \mathrm{C}$ (TGA); FTIR ( $\mathrm{cm}^{-1}$, ATR) 3065 (w) $\mathrm{C}_{\mathrm{sp} 2}-\mathrm{H}, 2930(\mathrm{w}) \mathrm{C}_{\mathrm{sp} 3}-\mathrm{H}, 1740$ (vs) ester carbonyl, 1598 (w) aromatic nucleus, 1186 (vs) C-O, 1162 (vs) $\mathrm{P}=\mathrm{O}, 927$ (s), $762(\mathrm{~s}) \mathrm{P}-\mathrm{O}-\mathrm{C} ;{ }^{1} \mathrm{H}-\mathrm{NMR}\left(\delta, \mathrm{CDCl}_{3}\right) 2.46(\mathrm{~m}, 4 \mathrm{H}$, methylene protons adjacent to phosphorus), 2.85 ( $\mathrm{m}, 4 \mathrm{H}$, methylene protons adjacent to carbonyl groups), 5.02 (s, $4 \mathrm{H}$, methylene protons adjacent to oxygen and a furan nucleus), 6.37 (s, 2H, furan protons), 7.14 and $7.29(\mathrm{~m}, 20 \mathrm{H}$, phenyl protons); ${ }^{13} \mathrm{C}-\mathrm{NMR}\left(\delta, \mathrm{CDCl}_{3}\right) 21.4$ (carbon atoms adjacent to phosphorus), 27.4 (carbon atoms adjacent to carbonyl groups), 58.6 (carbon atoms adjacent to oxygen), 111.9, 149.9 (furan carbon atoms), 120.5, 125.3, 129.8, 150.1 (phenyl carbon atoms), 171.2 (carbonyl carbon atoms); MS (ESI, $\mathrm{m} / \mathrm{z}$ ) 705.11 [M $+\mathrm{H}]^{+}, 727.07[\mathrm{M}+\mathrm{Na}]^{+}, 743.05[\mathrm{M}+\mathrm{K}]^{+}$.

2,2-Di[4-(3-dopylpropanoyl)phenyl]propane (DDPP). Mp $79{ }^{\circ} \mathrm{C}$ (DSC), $\mathrm{T}_{\mathrm{dec}} 373^{\circ} \mathrm{C}$ (TGA); FTIR $\left(\mathrm{cm}^{-1}\right.$, ATR) $3052(\mathrm{w}) \mathrm{C}_{\mathrm{sp} 2}-\mathrm{H}, 2973(\mathrm{~m}), 2862(\mathrm{w}) \mathrm{C}_{\mathrm{sp} 3}-\mathrm{H}, 1750(\mathrm{~s})$ ester carbonyl, $1625(\mathrm{w})$ aromatic nucleus, 1187 (s) $\mathrm{P}=\mathrm{O}, 1173$ (s) C-O, 901 (m), $743(\mathrm{~m}) \mathrm{P}-\mathrm{O}-\mathrm{C} ;{ }^{1} \mathrm{H}-\mathrm{NMR}\left(\delta, \mathrm{CDCl}_{3}\right) 1.61$ (s, 6H, methyl protons), $2.59(\mathrm{~m}, 4 \mathrm{H}$, methylene protons adjacent to phosphorus), $2.90(\mathrm{~m}, 4 \mathrm{H}$, methylene protons adjacent to carbonyl groups), $6.91-7.17$ ( $\mathrm{m}, 8 \mathrm{H}$, bisphenol protons), $7.21-8.01\left(\mathrm{~m}, 16 \mathrm{H}\right.$, dopyl protons); ${ }^{13} \mathrm{C}-\mathrm{NMR}(\delta$, $\left.\mathrm{CDCl}_{3}\right) 23.5$ (carbon atoms adjacent to phosphorus), 24.3 (carbon atoms adjacent to carbonyl groups), 30.9 (methyl carbon atoms), 42.5 (quaternary carbon atoms), 120.5-128.6, 130.1, 130.8, 133.6, 135.8, 148.0, 148.4, 148.9 (aromatic carbon atoms), 170.4 (carbonyl carbon atoms); ${ }^{31} \mathrm{P}-\mathrm{NMR}\left(\delta, \mathrm{CDCl}_{3}\right) 36.0$; MS (ESI, $m / z) 769.10[\mathrm{M}+\mathrm{H}]^{+}, 791.15[\mathrm{M}+\mathrm{Na}]^{+}, 807.11[\mathrm{M}+\mathrm{K}]^{+}$.

2,2-Di[3,5-dibromo-4-(3-dopylpropanoyl)phenyl]propane (DBDPP). M.p. $108^{\circ} \mathrm{C}$ (DSC); $\mathrm{T}_{\mathrm{dec}} 321^{\circ} \mathrm{C}$ (TGA); FTIR (cm ${ }^{-1}$, ATR) $3064(\mathrm{w}) \mathrm{C}_{\mathrm{sp} 2}-\mathrm{H}, 2970(\mathrm{w}), 2919(\mathrm{w}) \mathrm{C}_{\mathrm{sp} 3}-\mathrm{H}, 1770$ (vs) ester carbonyl, $1587(\mathrm{w})$ aromatic nucleus, 1249 (vs) C-O, 1123 (vs) $\mathrm{P}=\mathrm{O}, 917$ (s), 765 (s) $\mathrm{P}-\mathrm{O}-\mathrm{C} ;{ }^{1} \mathrm{H}-\mathrm{NMR}\left(\delta, \mathrm{CDCl}_{3}\right), 1.58$ (s, $6 \mathrm{H}$, methyl protons), 2.53 ( $\mathrm{m}, 4 \mathrm{H}$, methylene protons adjacent to phosphorus), 3.08 ( $\mathrm{m}, 4 \mathrm{H}$, methylene protons adjacent to carbonyl groups), $7.32(\mathrm{~s}, 4 \mathrm{H}$, protons of dibromophenyl groups), 7.21-7.98 (m, $16 \mathrm{H}$, dopyl protons); ${ }^{13} \mathrm{C}-\mathrm{NMR}\left(\delta, \mathrm{CDCl}_{3}\right) 24.1$ (carbon atoms adjacent to phosphorus), 26.3 (carbon atoms adjacent to carbonyl groups), 30.6 (methyl carbon atoms), 42.4 (quaternary carbon atoms), 117.4 (bromoaryl carbon atoms), 120.3, 121.9, 123.2, 124.1, 124.8, 125.3, 128.2, 128.8, 129.0, 130.1, 130.8, 133.6, 135.8, 144.3, 149.6 (aromatic carbon atoms), 168.2 (carbonyl carbon atoms); ${ }^{31} \mathrm{P}-\mathrm{NMR}\left(\delta, \mathrm{CDCl}_{3}\right) 36.0$; MS (ESI, $m / z) 1084.40[\mathrm{M}+\mathrm{H}]^{+}, 1106.78[\mathrm{M}+\mathrm{Na}]^{+}, 1122.75[\mathrm{M}+\mathrm{K}]^{+}$.

\section{Conclusions}

Bioderived bis-2,5-(hydroxymethyl)furan has been utilized as a base for the generation of a series of phosphorus compounds. The dihydroxy furan was converted to the corresponding bis-acrylate which was, in turn, subjected to Michael addition of phosphite to generate phosphorus derivatives with phosphorus linked through a $\mathrm{P}-\mathrm{C}$ bond. These compounds act as effective flame retardants in DGEBA epoxy. The DOPO derivative, 2,5-di[(3-dopylpropanoyl)methyl]furan, is the most effective. At a loading to provide $2 \%$ phosphorus in a DGEBA blend an LOI of 30 , a UL94 rating of V0 and a $40 \%$ reduction in peak heat release rate for combustion compared to that for resin containing no additive is observed. This performance is comparable to that observed for the analogous derivatives of bisphenol A and tetrabromobisphenol A diacrylates.

Supplementary Materials: The following are available online: Figure S1: The ${ }^{1} \mathrm{H}-\mathrm{NMR}$ Spectrum for Bisphenol A Diacrylate (BPADA), Figure S2: The ${ }^{13} \mathrm{C}-\mathrm{NMR}$ spectrum for bisphenol A diacrylate (BPADA), Figure S3: Infrared spectrum of bisphenol A diacrylate (BPADA), Figure 
S4: The ${ }^{1} \mathrm{H}-\mathrm{NMR}$ spectrum of 2,2-di[4-(3-dopylpropanoyl)phenyl]propane (DDPP), Figure S5: The ${ }^{13} \mathrm{C}-\mathrm{NMR}$ spectrum of 2,2-di[4-(3-dopylpropanoyl)phenyl]propane (DDPP), Figure S6: The DEPT NMR spectrum of 2,2-di[4-(3-dopylpropanoyl)phenyl]propane (DDPP), Figure S7: The gCOSY NMR spectrum of 2,2-di[4-(3-dopylpropanoyl)phenyl]propane (DDPP), Figure S8: The ${ }^{31} \mathrm{P}-\mathrm{NMR}$ spectrum of 2,2-di[4-(3-dopylpropanoyl)phenyl]propane (DDPP), Figure S9: ESI mass spectrum of 2,2-di[4-(3-dopylpropanoyl)phenyl]propane (DDPP), Figure S10: The ${ }^{1} \mathrm{H}-\mathrm{NMR}$ spectrum for tetrabromobisphenol A diacrylate (BBPADA), Figure S11: The ${ }^{13} \mathrm{C}$-NMR Spectrum for Tetrabromobisphenol A Diacrylate (BBPADA), Figure S12: The Infrared Spectrum of of tetrabromobisphenol A diacrylate (BBPADA), Figure S13: The ${ }^{1} \mathrm{H}-\mathrm{NMR}$ spectrum 2,2-di[3,5-dibromo-4-(3-dopylpropanoyl)phenyl]propane (DBDPP), Figure S14: The gCOSY NMR spectrum for 2,2-di[3,5-dibromo-4-(3-dopylpropanoyl)phenyl]propane (DBDPP), Figure S15: The DEPT NMR spectrum for 2,2-di[3,5-dibromo-4-(3-dopylpropanoyl)phenyl]propane (DBDPP), Figure S16: The ${ }^{13}$ C-NMR spectrum for 2,2-di[3,5-dibromo-4-(3-dopylpropanoyl)phenyl]propane (DBDPP), Figure S17: The HSQCAD NMR spectrum for 2,2-di[3,5-dibromo-4-(3-dopylpropanoyl)phenyl]propane (DBDPP), Figure S18: The infrared spectrum of 2,2-di[3,5-dibromo-4-(3-dopylpropanoyl)phenyl]propane (DBDPP), Figure S19: The ESI mass spectrum of 2,2-di[3,5-dibromo-4-(3-dopylpropanoyl)phenyl]propane (DBDPP), Figure S20: The ${ }^{1} \mathrm{H}-\mathrm{NMR}$ spectrum for 2,5-bis-(hydroxymethyl)furan diacrylate (BHFDA), Figure S21: The ${ }^{13}$ C-NMR spectrum for 2,5-bis-(hydroxymethyl)furan diacrylate (BHFDA), Figure S22: The infrared spectrum for 2,5-bis-(hydroxymethyl)furan diacrylate (BHFDA), Figure S23: Mass spectrum for 2,5-bis-(hydroxymethyl)furan diacrylate (BHFDA), Figure S24: The ${ }^{1} \mathrm{H}-\mathrm{NMR}$ spectrum for 2,5-di[(3-dopylpropanoyl)methyl]furan (DDMF), Figure S25: The gCOSY NMR spectrum for 2,5-di[(3-dopylpropanoyl)methyl]furan (DDMF), Figure S26: The ${ }^{13}$ C-NMR spectrum for 2,5-di[(3-dopylpropanoyl)methyl]furan (DDMF), Figure S27: The DEPT NMR spectrum for 2,5-di[(3-dopylpropanoyl)methyl]furan (DDMF), Figure S28: The HSQCDA NMR spectrum for 2,5-di[(3-dopylpropanoyl)methyl]furan (DDMF), Figure S29: The infrared spectrum of 2,5-di[(3-dopylpropanoyl)methyl]furan (DDMF), Figure S30: The ESI mass spectrum of 2,5-di[(3-dopylpropanoyl)methyl]furan (DDMF), Figure S31: The ${ }^{1} \mathrm{H}-\mathrm{NMR}$ spectrum for di[(3-diethylphosphonatopropanoyl)methyl]furan (DEMF), Figure S32: The ${ }^{13}$ C-NMR spectrum for di[(3-diethylphosphonatopropanoyl)methyl]furan (DEMF), Figure S33: The infrared spectrum of di[(3-diethylphosphonatopropanoyl)methyl]furan (DEMF), Figure S34: The ESI mass spectrum of di[(3-diethylphosphonatopropanoyl)methyl]furan (DEMF), Figure S35: The ${ }^{1} \mathrm{H}-\mathrm{NMR}$ spectrum for di[(3-diphenylphosphonatopropanoyl)methyl]furan (DPMF), Figure S36: The ${ }^{13}$ C-NMR spectrum for di[(3-diphenylphosphonatopropanoyl)methyl]furan (DPMF), Figure S37: The infrared spectrum for di[(3-diphenylphosphonatopropanoyl)methyl]furan (DPMF), Figure S38: The ESI mass spectrum for di[(3-diphenylphosphonatopropanoyl)methyl]furan (DPMF).

Author Contributions: Conceptualization, B.A.H.; Investigation, X.H.; Project administration, B.A.H.; Validation, X.H.; Writing - original draft, B.A.H. All authors have read and agreed to the published version of the manuscript.

Funding: This research received no external funding.

Acknowledgments: Biobased bis-2,5-(hydroxymethyl)furan was generously supplied by PennAKem, LLC, Nashville, TN. Diphenylchlorophosphate was provided by ICL-IP America, Inc. and DGEBA by the Dow Chemical Company.

Conflicts of Interest: The authors declare no conflict of interest.

Sample Availability: Samples of the compounds are available from the authors.

\section{References}

1. Halary, J.-L.; Laupretre, F.; Monnerie, L. Polymer Materials; John Wiley and Sons, Inc.: Hoboken, NJ, USA, 2011.

2. Binder, W.H. The Past 40 years of Macromolecular Sciences: Reflections on Challenges in Synthetic and Material Science. Macrol. Rapid Commun. 2019, 40, e1800610. [CrossRef] [PubMed]

3. Lecommandoux, S.; Klok, H.-A.; Zhong, Z.; Deming, T.J. Future Directions at the Frontier of Polymer Science and Biology. Biomacromolecules 2019, 20, 1-3. [CrossRef] [PubMed]

4. Zhang, M.; Buekens, A.; Li, X. Brominated Flame Retardants and the Formation of Dioxins and Furans in Fires and Combustion. J. Hazard. Mater. 2016, 304, 26-39. [CrossRef] [PubMed]

5. Cristale, J.; Belé, T.G.A.; Lacorte, S.; de Marchi, M.R.R. Occurrence of Flame Retardants in Landfills: A Case Study in Brazil. Environ. Res. 2019, 168, 420-427. [CrossRef]

6. Darnerud, P.O. Brominated Flame Retardants as Possible Endocrine Disrupters. Int. J. Androl. 2008, 31, 152-160. [CrossRef] 
7. Legler, J.; Brouwer, A. Are Brominated Flame Retardants Endocrine Disruptors? Environ. Int. 2003, 29, 879-885. [CrossRef]

8. Sjödin, A.; Patterson, D.G.; Bergman, A. A Review of Human Exposure to Brominated Flame Retardants-Particularly Polybrominated Diphenyl Ethers. Environ. Int. 2003, 29, 829-839. [CrossRef]

9. Alace, M.; Wenning, R.J. The Significance of Brominated Flame Retardants in the Environment: Current Understanding, Issues and Challenges. Chemosphere 2002, 5, 579-582.

10. Axelrad, D. Brominated Flame Retardants: Regulatory Actions and EPA Activities; U.S. Environmental Protection Agency: Washington, DC, USA, 2009.

11. Hogue, C. EU Authorization Said to be Leading to Safer Substitutes. Chem. Eng. News 2017, 95, 15.

12. Hess, G. Industry Drops Flame Retardant. Chem. Eng. News 2010, 88, 10. [CrossRef]

13. Velencoso, M.M.; Battig, A.; Markwart, J.C.; Schartel, B.; Wurm, F.R. Molecular Firefighting-How Modern Phosphorus Chemistry Can Help Solve the Challenge of Flame Retardancy. Angew. Chem. Int. Ed. 2018, 57, 10450-10467. [CrossRef]

14. Morgan, A.B. The Future of Flame Retardant Polymers-Unmet Needs and Likely New Approaches. Polym. Rev. 2019, 59, 25-54. [CrossRef]

15. Van der Veen, I.; de Boer, J. Phosphorus Flame Retardants: Properties, Production, Environmental Occurrence, Toxicity and Analysis. Chemosphere 2012, 88, 1119-1153. [CrossRef] [PubMed]

16. Hirsch, C.; Striegl, R.; Mathes, S.; Adhart, C.; Edelmann, M.; Bono, E.; Gaan, S.; Salmeia, K.A.; Hoelting, L.; Krebs, A.; et al. Multiparameter Toxicity Assessment of Novel DOPO-derived Organophosphorus Flame Retardants. Arch. Toxicol. 2017, 91, 407-425. [CrossRef]

17. Liu, M.; Yin, H.; Chen, X.; Yang, J.; Liang, Y.; Zhang, J.; Yang, F.; Deng, Y.; Lu, S. Preliminary Ecotoxicity Hazard Evaluation of DOPO-HQ as a Potential Alternative to Halogenated Flame Retardants. Chemosphere 2018, 193, 126-133. [CrossRef]

18. Zhao, W.; Li, B.; Xu, M.; Zhang, L.; Liu, F.; Guan, L. Synthesis of a Novel Flame Retardant Containing Phosphorus and Sulfur and Its Application in Polycarbonate. Polym. Eng. Sci. 2012, 52, 2327-2335. [CrossRef]

19. Braun, U.; Knoll, U.; Schartel, B.; Hoffmann, T.; Pospiech, D.; Artner, J.; Ciesielski, M.; Doring, M.; Perez-Graterol, R.; Sandler, J.K.W.; et al. Novel Phosphorus-containing Poly(ether sulfone)s and Their Blends with an Epoxy Resin: Thermal Decomposition and Fire Retardancy. Macromol. Chem. Phys. 2006, 207, 1501-1514. [CrossRef]

20. Wagner, J.; Deglmann, P.; Fuchs, S.; Ciesielski, M.; Fleckenstein, C.A.; Döring, M. A Flame Retardant Synergism of Organic Disulfides and Phosphorous Compounds. Polym. Degrad. Stab. 2016, 129, 63-76. [CrossRef]

21. Howell, B.A.; Daniel, Y.G. The Impact of Sulfur Oxidation Level on Flame Retardancy. J. Fire Sci. 2018, 36, 518-534. [CrossRef]

22. Neisius, N.M.; Lutz, M.; Rentsch, D.; Hemberger, P.; Gaan, S. Synthesis of DOPO-based Phosphonamidates and Their Thermal Properties. Ind. Eng. Chem. Res. 2014, 53, 2889-2896. [CrossRef]

23. Salmeia, K.A.; Gaan, S. An Overview of Some Recent Advances in DOPO-Derivatives: Chemistry and Flame Retardant Applications. Polym. Degrad. Stab. 2015, 113, 119-134. [CrossRef]

24. Dumitrascu, A.; Howell, B.A. Flame Retardant Polymeric Materials Achieved by Incorporation of Styrene Monomers Containing Both Nitrogen and Phosphorus. Polym. Degrad. Stab. 2012, 97, 2611-2618. [CrossRef]

25. Yan, Y.; Liang, B. Flame-retardant Behavior and Mechanism of a DOPO-based Phosphorus-nitrogen Flame Retardant in Epoxy Resin. High Per. Polym. 2019, 31, 885-892. [CrossRef]

26. Wang, P.; Chen, L.; Xiao, H. Flame Retardant Effect and Mechanism of a Novel DOPO Based Tetrazole Derivative on Epoxy Resin. J. Anal. Appl. Pyrolysis 2019, 139, 104-113. [CrossRef]

27. Nazir, R.; Gaan, S. Recent Developments in P (O/S)-N Containing Flame Retardants. J. Appl. Polym. Sci. 2019, 137, 47910. [CrossRef]

28. Tang, S.; Qian, L.J.; Qiu, Y.; Dong, Y.P. Synergistic Flame-retardant Effect and Mechanisms of Boron/phosphorus Compounds on Epoxy Resins. Polym. Advan. Technol. 2018, 29, 641-648. [CrossRef]

29. Tang, S.; Qian, L.J.; Qiu, Y.; Dong, Y.P. High-performance Flame Retardant Epoxy Resin Based on a Bi-Group Molecule Containing Phosphaphenanthrene and Borate Groups. Polym. Degrad. Stab. 2018, 153, 210-219. [CrossRef] 
30. Zhang, W.C.; Li, X.M.; Yang, R.J. Pyrolysis and Fire Behavior of Epoxy Resin Composites Based on a Phosphorus-containing Polyhedral Oligomeric Silsesquioxane (DOPO-POSS). Polym. Degrad. Stab. 2011, 96, 1821-1832. [CrossRef]

31. Qian, Y.; Wei, P.; Hao, J.W. Preparation of Hybrid Phosphamide Containing Polysilsesquioxane and Its Effect on Flame Retardancy and Mechanical Properties of Polypropylene Composites. Compos. B. Eng. 2013, 45, 1541-1547. [CrossRef]

32. Zhang, W.; Li, X.; Li, L.; Yang, R. Study of the Synergistic Effect of Silicon and Phosphorus on the Blowing-out Effect of Epoxy Resin Composites. Polym. Degrad. Stab. 2012, 97, 1041-1048. [CrossRef]

33. Sag, J.; Goedderz, D.; Kubla, P.; Griener, L.; Schonberger, F.; Doring, M. Phosphorus-containing Flame Retardants from Biobased Chemicals and their Application in Polyesters and Epoxy Resins. Molecules 2019, 24, 3746. [CrossRef]

34. Howell, B.A.; Daniel, Y.G.; Ostrander, E.A. Flame Retardants from Renewable Sources: Food Waste, Plant Oils, and Starch. In Green Polymer Chemistry: New Products, Processes, and Applications; Cheng, H.N., Smith, P.B., Eds.; American Chemical Society: Washington, DC, USA, 2018; pp. 405-421.

35. Sonnier, R.; Taguet, A.; Ferry, L.; Lopez-Cuesta, J.M. Towards Biobased Flame Retardant Polymers; Springer International Publishing AG: Cham, Switzerland, 2018.

36. Costes, L.; Laoutid, F.; Brohez, S.; Dubois, P. Biobased Flame Retardants: When Nature Meets Fire Protection. Mater. Sci. Eng. R 2017, 117, 1-25. [CrossRef]

37. Xia, Z.; Kiratitanavit, W.; Facendola, P.; Thota, S.; Yu, S.; Kumar, J.; Mosurkal, R.; Nagarajan, R. Fire Resistant Polyphenols Based on Chemical Modification of Bioderived Tannic Acid. Polym. Degrad. Stab. 2018, 153, 227-243. [CrossRef]

38. Howell, B.A.; Daniel, Y.G. Thermal Degradation of Phosphorus Esters Derived From Isosorbide and 10-Undecenoic Acid. J. Therm. Anal. Calorim. 2015, 121, 411-419. [CrossRef]

39. Daniel, Y.G.; Howell, B.A. Flame Retardant Properties of Isosorbide bis-Phosphorus Esters. Polym. Degrad. Stab. 2017, 140, 25-31. [CrossRef]

40. Hu, C.; Bourbigot, S.; Delaunay, T.; Collinet, M.; Marcille, S.; Fontaine, G. Synthesis of Isosorbide Based Flame Retardants: Application for Polybutylene Succinate. Polym. Degrad. Stab. 2019, 164, 9-17. [CrossRef]

41. Howell, B.A.; Sun, W. Biobased Flame Retardants From Tartaric Acid and Derivatives. Polym. Degrad. Stab. 2018, 157, 199-211. [CrossRef]

42. Howell, B.A.; Oberdorfer, K.L.; Ostrander, E.A. Phosphorus Flame Retardants for Polymeric Materials from Gallic Acid and Other Naturally Occurring Multihydroxybenzoic Acids. Int. J. Polym. Sci. 2018, 2018, 7237236. [CrossRef]

43. Howell, B.A.; Alrubayyi, A. 2-Dopyl-1,4-di(2-dopylpropanoyl)benzene, An Effective Phosphorus Flame Retardant. Polym. Degrad. Stab. 2019, 162, 196-200. [CrossRef]

44. Ménard, R.; Negrell, C.; Ferry, L.; Sonnier, R.; David, G. Synthesis of Biobased Phosphorus-containing Flame Retardants for Epoxy Thermosets Comparison of Additive and Reactive Approaches. Polym. Degrad. Stab. 2015, 120, 300-312. [CrossRef]

45. Ménard, R.; Negrell, C.; Fache, M.; Ferry, L.; Sonnier, R.; David, G. From a Biobased Phosphorus-containing Epoxy Monomer to Fully Biobased Flame-retardant Thermosets. RSC Adv. 2015, 5, 70856-70867. [CrossRef]

46. Princen, L.H. Alternate Industrial Feedstocks From Agriculture. Econ. Bot. 1982, 36, 302-312. [CrossRef]

47. Miller, D. The Bioharvest Is Here. The Progressive Farmer. 2018, pp. 22-25. Available online: http://dtnpf-digital.com/publication/?i=495985\&article_id=3086440\&view=articleBrowser\&ver=html5\# |protect \T1 \textbraceleft\%22issue_id\%22:495985,\%22view\%22:\%22articleBrowser\%22,\%22publication_id\% 22:\%2227946\%22,\%22article_id\%22:\%223086440\%22〈protect|T1 \textbraceright (accessed on 24 January 2020).

48. Hong, J.; Radojčić, D.; Ionescu, M.; Petrović, Z.S.; Eastwood, E. Advanced Materials From Corn: Isosorbide-based Epoxy Resins. Polym. Chem. 2014, 5, 5360-5368. [CrossRef]

49. Corma, A.; Iborra, S.; Velty, A. Chemical Routes for the Transformation of Biomass into Chemicals. Chem. Rev. 2007, 107, 2411-2502. [CrossRef] [PubMed]

50. Van Putten, R.J.; van der Waal, J.C.; de Jong, E.; Rasrendra, C.B.; Heeres, H.J.; de Vries, J.G. Hydroxymethylfurfural, A Versatile Platform Chemical Made From Renewable Resources. Chem. Rev. 2013, 113, 1499-1597. [CrossRef] [PubMed]

51. Teong, S.P.; Yi, G.; Zhang, Y. Hydroxymethylfurfural Production From Bioresources: Past, Present and Future. Green Chem. 2014, 16, 2015-2026. [CrossRef] 
52. Wang, T.; Nolte, M.W.; Shanks, B.H. Catalytic Dehydration of $\mathrm{C}_{6}$ Carbohydrates for the Production of Hydroxymethylfurfural (HMF) as a Versatile Platform Chemical. Green Chem. 2014, 16, 548-572. [CrossRef]

53. Jiang, Y.; Woortman, A.J.J.; Alberda van Ekenstein, G.O.R.; Petrović, D.M.; Loos, K. Enzymatic Synthesis of Biobased Polyesters Using 2,5-bis(Hydroxymethyl)furan as the Building Block. Biomacromolecules 2014, 15, 2482-2493. [CrossRef]

54. Zeng, C.; Seino, H.; Ren, J.; Hatanaka, K.; Yoshie, N. Biobased Furan Polymers with Self-healing Ability. Macromolecules 2013, 46, 1794-1802. [CrossRef]

55. Zhang, Y.; Li, T.; Xie, Z.; Han, J.; Xu, J.; Guo, B. Synthesis and Properties of Biobased Multiblock Polyesters Containing Poly(2,5-furandimethylene succinate) and Poly (butylene succinate) Blocks. Ind. Eng. Chem. Res. 2017, 56, 3937-3946. [CrossRef]

56. Choi, E.H.; Lee, J.; Son, S.U.; Song, C. Biomass-derived Furanic Polycarbonates: Mild Synthesis and Control of the Glass Transition Temperature. J. Polym. Sci. Polym. Chem. 2019, 57, 1796-1800. [CrossRef]

57. Howell, B.A.; Lazar, S.T. Biobased Plasticizers From Carbohydrate-derived 2,5-bis (Hydroxymethyl) furan. Ind. Eng. Chem. Res. 2018, 58, 1222-1228. [CrossRef]

58. Daniel, Y.G.; Howell, B.A. Phosphorus Flame Retardants From Isosorbide bis-Acrylate. Polym. Degrad. Stab. 2018, 156, 14-21. [CrossRef]

59. Wendels, S.; Chavez, T.; Bonnet, M.; Salmeia, K.A.; Gaan, S. Recent Developments in Organophosphorus Flame Retardants Containing P-C Bond and their Application. Materials 2017, 10, 784. [CrossRef] [PubMed]

60. Müller, P.; Bykov, Y.; Döring, M. New Star-shaped Phosphorus-containing Flame Retardants Based on Acrylates for Epoxy Resins. Polym. Adv. Technol. 2013, 24, 834-840. [CrossRef]

61. Rabe, S.; Chuenban, Y.; Schartel, B. Exploring the Modes of Action of Phosphorus-based Flame Retardants in Polymeric Systems. Materials 2017, 10, 455. [CrossRef]

62. Schartel, B.; Perret, B.; Dittrich, B.; Ciesielski, M.; Krämer, J.; Müller, P.; Alstadt, V.; Zang, L.; Döring, M. Flame Retardancy of Polymers: the Role of Specific Reactions in the Condensed Phase. Macromol. Mater. Eng. 2016, 301, 9-35. [CrossRef]

63. Braun, U.; Balabanovich, A.I.; Schartel, B.; Knoll, U.; Artner, J.; Ciesielski, M.; Doring, M.; Perez, R.; Sandler, J.K.W.; Altstadt, V.; et al. Influence of the Oxidation State of Phosphorus on the Decomposition and Fire Behavior of Flame-retarded Epoxy Resin Composites. Polymer 2006, 47, 8495-8508. [CrossRef]

64. Balabanovich, A.I.; Pospiech, D.; Häußler, L.; Harnisch, C.; Döring, M. Pyrolysis Behavior of Phosphorus Polyesters. J. Anal. Appl. Pyrolysis 2009, 86, 99-107. [CrossRef]

65. Salmeia, K.A.; Fage, J.; Liang, S.; Gaan, S. An Overview of Mode of Action and Analytical Methods for Evaluation of Gas Phase Activities of Flame Retardants. Polymers 2015, 7, 504-526. [CrossRef]

66. Liang, S.; Hemberger, P.; Neisius, N.M.; Bodi, A.; Grützmacher, H.; Levalois-Grützmacher, J.; Gaan, S. Elucidating the Thermal Decomposition of Dimethyl Methylphosphonate by Vacuum Ultraviolet (VUV) Photoionization: Pathways to the PO Radical, A Key Species in Flame-retardant Mechanisms. Chem. Eur. J. 2015, 21, 1073-1080. [CrossRef] [PubMed]

67. Howell, B.A.; Cho, Y.J. Brominated Aryl Phospholanes as Dual Functional Flame Retardants for Polymeric Materials. Polym. Mater. Sci. Eng. 2008, 98, 361.

68. Howell, B.A. Development of Additives Possessing both Solid-phase and Gas-phase Flame Retardant Activities. Polym. Degrad. Stab. 2008, 93, 2052-2057. [CrossRef]

(C) 2020 by the authors. Licensee MDPI, Basel, Switzerland. This article is an open access article distributed under the terms and conditions of the Creative Commons Attribution (CC BY) license (http://creativecommons.org/licenses/by/4.0/). 